Revista do CESP, Belo Horizonte, v.36, n.55, p. 49-63, 2016

\title{
O tédio no Livro do desassossego
}

\section{The tedium in The book of disquiet}

\author{
Adriano de Oliveira \\ Universidade Católica Portuguesa, Braga / Portugal \\ ms.oliveira1976@gmail.com
}

Resumo: O Livro do desassossego representa um dos escritos mais relevantes e significativos do autor português Fernando Pessoa. A obra compreende uma coletânea de textos diversos assinados, em sua maioria, por Bernardo Soares. Em razão de sua estrutura e complexidade temática, o Livro do desassossego aborda situações, sentimentos e assuntos bastante variados, entre os quais se destaca o tema do tédio. $\mathrm{O}$ interesse fundamental deste artigo é considerar o estado entediado, sob as perspectivas da sua compreensão, das causas de sua manifestação e das tentativas ou atitudes convenientes para a sua superação. Esta análise limita-se à leitura corrente da obra do Ajudante de guarda-livros na cidade de Lisboa, mantendo sua especial atenção às ocasiões onde a palavra tédio aparece.

Palavras-chave: aborrecimento generalizado; desassossego; indiferença; sentido existencial; tédio.

Abstract: The Book of Disquiet represents one of the most relevant and significant writings of the Portuguese writer Fernando Pessoa. The work consists of a compilation of various texts and most of them are attributed to Bernardo Soares. Due to its structure and thematic complexity, The Book of disquiet takes into consideration very different subjects, situations and feelings, among which stands out the theme of tedium. The main purpose of this article is to consider the case of being tedious, under the perspective of its understanding, the causes of its manifestation and the 
attempts for its overcoming. This analysis is circumscribed to the book of the Assistant bookkeeper in the City of Lisbon, focusing a special attention to the occasions where the word tedium appears.

Keywords: boredom; disquiet; indifference; existential meaning; tedium.

Data de recebimento: 23 de fevereiro de 2016

Data de aprovação: 2 de março de 2016

\section{Considerações iniciais}

O enfrentamento dos escritos pessoanos exige, de modo geral, dedicação, esforço e coragem do leitor. Isto se torna mais sério e grave quando se pretende a leitura do Livro do desassossego. Apesar do contrassenso da afirmação que se segue, esta obra é, praticamente, inclassificável. Ela se constitui uma espécie de labirinto literário, composto por um vasto conjunto de devaneios, de pensamentos soltos, sem nítidos elementos de conexão, marcado por contradições e mudanças de opinião e cuja autoria principal é atribuída ao semi-heterônimo Bernardo Soares. Richard Zenith (apud PESSOA, 2013, p. 13-17) declara, nos pontos iniciais da sua introdução, que essa obra de Fernando Pessoa é a imagem fiel do livro "que nunca existiu [...] e que nunca poderá existir". Numa possível analogia e vinculação com a vida do escritor português, o comentador assevera que o texto traz consigo o caráter da incerteza e do inacabamento.

Conscientes da complexidade própria das reflexões expressas pelo Ajudante de guarda-livros na cidade de Lisboa, o objetivo do artigo que ora se apresenta é considerar o tema do tédio, no que diz respeito aos seus sentidos principais, às ocasiões de sua emergência e às possibilidades de seu afastamento ou superação. A escolha do termo justifica-se em razão do fato de ser o único que no Livro do desassossego merece duas tentativas de elucidação. Ele se mostra como um dos indicativos mais frequentes do estado emocional de Bernardo Soares, sendo repetido, seguidamente, por volta de quinze vezes, nos textos 263 e 381 . E, sobretudo, por se tratar de uma expressão qualificadora e reveladora da dimensão existencial do próprio Fernando Pessoa (SERRÃO, 1983, 
p. 125, 143). Ressalta-se que este estudo se limita à análise da obra em tela, concentrando-se nos textos onde o termo tédio é utilizado explicitamente. ${ }^{1}$

\section{Os sentidos do termo}

O primeiro escrito publicado por Fernando Pessoa que assume o tédio enquanto tema foi Na floresta do alheamento. A maneira como a expressão é tomada aqui reflete-se, praticamente, em todo o Livro do desassossego, pois busca traduzir o cansaço de ser e de existir ou mesmo revelar um tipo de angústia intensa que atinge e invade a alma. ${ }^{2}$ Agora, realizando a leitura corrente do texto de Bernardo Soares, o estar entediado, antes de receber definições ou ser elucidado, é apresentado de modo analógico ou comparativo. Ele aparece como expressão de certo desdém por aqueles que, ao optarem pela humanidade e pelo mundo exterior, olvidam-se do que realmente vale a pena, ou seja, o cuidado e o cultivo da dimensão interior. Deste modo, o tédio, enquanto confusão e perturbação do sentir, configura-se como uma ameaça constante à vida dedicada aos sonhos e à escrita (PESSOA, 2013, n. 35, 45, 47).

Aos poucos, Bernardo Soares alarga e aprofunda as aproximações e as correlações dos significados do termo no desenrolar de seu texto. O pessimismo, a infelicidade, o fracasso existencial, a vida não realizada,

\footnotetext{
${ }^{1} \mathrm{Na}$ edição do Livro do desassossego (PESSOA, 2013) usada para esta pesquisa, a palavra tédio aparece cerca de 144 vezes, conforme a seguinte distribuição: 2 vezes no Prefácio (p. 44); 118 vezes em Autobiografia sem factos (números 14, 35, 45, 47, 50, 55, 61, 75, 78, 82, 98, 99, 101, 105, 122, 142, 151, 155, 181, 182, 184, 191, 193, 204, $215,235,260,263,265,277,278,285,299,312,314,320,336,337,342,345,365$, $370,371,380,381,382,385,404,410,414,418,426,442,445,446,449,454,464$, 465); 19 vezes em Os grandes trechos (p. 427, 441, 457, 459, 460, 461, 462, 463, 466, 476, 477, 486, 487); e 5 vezes em Apêndice (p. 496, 497, 502, 504).

${ }^{2}$ Em maio de 1914, Fernando Pessoa escreveu uma carta a João de Lebre e Lima, na qual pergunta ao seu correspondente se este havia visto Na floresta do alheamento numa das edições de A Águia, publicada no ano anterior. Caso negativo, o próprio Pessoa iria encaminhar a Lebre e Lima uma cópia do material. Na floresta do alheamento é incluído pelo editor Richard Zenith no Livro do desassossego no conjunto de Os grandes trechos. (PESSOA, 2013, p. 456-462, 504). Joel Serrão (1983, p. 125-126) aponta outros textos epistolares coetâneos à publicação de Na floresta do alheamento, nos quais Pessoa considera o tema do tédio ou fala de seu próprio estado entediado.
} 
o medo de colocar-se em condição de riscos reais, a pobreza de sensibilidade e a sensação de vazio passam a fazer parte da sua noção ampliada do tédio (PESSOA, 2013, n. 61, 75, 82, 182). A certa altura,ele realiza uma confissão dramática acerca do caráter absurdo e ilógico daquilo que vivencia, bem como constata o surgir espontâneo e sem porquê do seu sentimento:

Acordei hoje muito cedo, num repente embrulhado, e ergui-me logo da cama, sob o estrangulamento de um tédio incompreensível. Nenhum sonho o havia causado; nenhuma realidade o poderia ter feito. Era um tédio absoluto e completo, mas fundado em qualquer coisa. No fundo obscuro da minha alma, invisíveis, forças desconhecidas travavam uma batalha em que meu ser era o solo, e todo eu tremia do embate incógnito. Uma náusea física da vida inteira nasceu com o meu despertar. Um horror a ter que viver ergueu-se comigo da cama. Tudo me pareceu oco e tive a impressão fria de que não há solução para problema algum. Uma inquietação enorme fazia-me estremecer os gestos mínimos. Tive receio de endoidecer, não de loucura, mas de ali mesmo. O meu corpo era um grito latente. $\mathrm{O}$ meu coração batia como se soluçasse. (PESSOA, 2013, n. 98)

É digno de nota que o Ajudante de guarda-livros admite-se um sujeito dado ao tédio, mas que, até então, não havia refletido a respeito da natureza de tal disposição. Assim, e devido ao seu estado de ânimo, resolve cumprir esta tarefa. De imediato, ele percebe as dificuldades em identificar as ocasiões de manifestação do tédio e o problema de associá-las às questões temporais, corporais ou causais evidentes em sua vida. Segundo Soares, outro ponto intricado sobre a tipificação do referido sentimento é que ele pode se apresentar como angústia metafísica, desilusão desconhecida, aborrecimento, ou tudo isto junto ou algo semelhante. Ele mostra entender que o tédio traz consigo elementos paradoxais, contraditórios e é melhor expresso através de comparações e ou metáforas (PESSOA, 2013, n. 263).

O tédio... Pensar sem que se pense, com o cansaço de pensar; sentir sem que se sinta, com a angústia de sentir; não querer sem que se não queira, com a náusea de não querer - tudo isto está no tédio sem ser o tédio, nem é 
dele mais que uma paráfrase ou uma translação. E, na sensação directa, como se de sobre o fosso do castelo da alma se erguesse a ponte levadiça, nem restasse, entre o castelo e as terras, mais que o poder olhá-las sem as poder percorrer. Há um isolamento de nós em nós mesmos, mas um isolamento onde o que separa está estagnado como nós, água suja cercando o nosso desentendimento. $\mathrm{O}$ tédio... Sofrer sem sofrimento, querer sem vontade, pensar sem raciocínio... É como a possessão por um demónio negativo, um embruxamento por coisa nenhuma. Dizem que os bruxos, ou os pequenos magos, conseguem, fazendo de nós imagens, e a elas infligindo maus tratos, que esses maus tratos, por uma transferência astral, se reflictam em nós. O tédio surge-me, na sensação transposta desta imagem, como o reflexo maligno de bruxedos de um demónio de fadas, exercido, não sobre uma imagem minha, senão sobre a sua sombra. É na sombra íntima de mim, no exterior do interior da minha alma, que se colam os papéis ou se espetam alfinetes. Sou como o homem que vendeu a sombra, ou, antes, como a sombra do homem que a vendeu. (PESSOA, 2013, n. 263)

Ainda no mesmo processo de análise, Bernardo Soares vincula o sentir-se entediado às imagens do cansaço de si próprio, do fel da inércia da alma, da experiência do vácuo. Além disso, numa espécie de apropriação religiosa, a sensação de tédio é descrita como uma insatisfação da alma humana por não ter uma crença, o desolamento dela por não entreter-se com o divino, ou o seu caminhar inseguro no caminho negro da sensação por lhe faltar uma companhia apta a guiá-la e conduzi-la no pensar e no sentir. E, então, declara

O tédio... Quem tem Deuses nunca tem tédio. O tédio é uma falta de mitologia. A quem não tem crenças, até a dúvida é impossível, até o cepticismo não tem força para desconfiar. Sim, o tédio é isso: a perda, pela alma, da sua capacidade de se iludir, a falta, no pensamento, da escada inexistente por onde ele sobe à verdade. (PESSOA, 2013, n. 263)

Há uma segunda exposição ostensiva do assunto em tela no fragmento de número 381 . Neste é asseverado que não foi estabelecida 
uma apresentação suficiente do tédio, de modo que alguém que nunca o tenha sofrido seja capaz de ter uma ideia clara do que ele vem a ser. Diante disso, Soares reconhece os esforços incompletos e restritos em equiparar o tédio ao aborrecimento, ao cansaço e ao mal-estar. Todavia, ele alerta que aquele inclui todos estes, sem lhes ser igual. Por outro lado, ele afirma que se costuma identificar o estar entediado a uma noção que o ultrapassa que é a do "desgosto íntimo e espiritual da variedade e das incertezas do mundo." (PESSOA, 2013, n.381). Ao que tudo indica, tal disposição, ao invés de conduzir ao tédio, apresenta-se como a fonte original da genialidade e do misticismo. Após essas explicações, Bernardo detalha a sua percepção densa e singular do tédio.

O tédio é, sim, o aborrecimento do mundo, o mal-estar de estar vivendo, o cansaço de se ter vivido; o tédio é, deveras, a sensação carnal da vacuidade prolixa das coisas. Mas o tédio é, mais do que isto, o aborrecimento de outros mundos, quer existam quer não; o mal-estar de ter que viver, ainda que outro, ainda que de outro modo, ainda que noutro mundo; o cansaço, não só de ontem e de hoje, mas de amanhã também, da eternidade, se a houver, e do nada, se é ele que é a eternidade. Nem é só a vacuidade das coisas e dos seres que dói na alma quando ela está em tédio: é também a vacuidade de outra coisa qualquer, que não as coisas e os seres, a vacuidade da própria alma que sente o vácuo, que se sente vácuo, e que nele de si se enoja e se repudia. O tédio é a sensação física do caos, e de que o caos é tudo. (PESSOA, 2013, n. 381)

Enquanto o aborrecido, o que tem mal-estar e o que está cansado encontram-se, por assim dizer, atados, numa cela estreita; e o desgostoso da vida, algemado, numa cela ampla; aquele que tem tédio "sente-se preso em liberdade fruste numa cela infinita". Aos quatro primeiros, a ocorrência de algo de natureza exterior - por exemplo, a derrubada das paredes ou a soltura das amarras - poderia acabar com os seus sofrimentos. Contudo, ao entediado, nada que suceder o afetará, pois os muros que o cerram não existem e algemas que o seguram não lhe foram colocadas. O seu drama existencial tem raízes mais profundas e é sofrido de modo mais radical e intenso (PESSOA, 2013, n.381).

Sob a figura emblemática do cárcere, Soares estabelece uma espécie de associação do tédio ao estado de inércia ou paralisia do ser. 
Em tal situação, a pessoa encarcerada se vê condenada a viver só o real e a conceber apenas o possível (PESSOA, 2013, p. 477, 486, 502). Neste sentido, é bastante significativa a contraposição, proposta por José Gil (2013, p. 95-96, 101-106), entre o desassossego e o tédio. O referido autor compreende o primeiro como o puro devir, enquanto o segundo é visto como a clausura, a estagnação, ou, valendo da imagem usada pelo próprio Bernardo Soares, como a prisão da pessoa na cela infinita. José Gil diz ainda que o desassossego e a inquietude d'alma encontram-se diretamente vinculados ao poder criativo e à façanha heteronímica de Fernando Pessoa, ao passo que o tédio emerge e se firma como a paragem catastrófica destes movimentos. ${ }^{3}$

É exatamente o tipo de aprisionamento relacionado nos parágrafos anteriores que Bernardo Soares sente ao contemplar a beleza da tarde que cai e ao vislumbrar um enfadamento peculiar no que está a ver. Ele intui que aquilo que se mostra diante de si não passa de um reflexo do seu interior. Destarte, o Ajudante de guarda-livros anuncia a sua tomada de consciência do nível real em que se situa: "Cheguei àquele ponto em que o tédio é uma pessoa, a ficção encarnada do meu convívio comigo mesmo" (PESSOA, 2013, n. 382). A imagem e o significado mais falantes e evidentes da expressão do tédio são a sua própria existência. Com esta definição visual, passamos ao segundo ponto da reflexão.

\footnotetext{
3 "Na verdade, é supondo um eu petrificado, dividido entre dois polos congelados, que Bernardo Soares caracteriza o tédio pela projecção do eu no mundo. Assim, também o mundo se petrifica. Neste sentido poder-se-ia considerar o tédio como o avesso do desassossego (no seu regime de produção do sonho): este supõe um movimento, em princípio, perpétuo, aquele, a paralisação de todo o movimento. O desassossego é o puro movimento da vida, indo sempre além dos pólos opostos que encontra; o tédio esvazia o mundo e o sonhador de toda a vida, congelando os contrários e fazendo desaparecer o movimento; o desassossego pode libertar, o tédio aprisiona; o desassossego dissolve o eu, o tédio enquista-o de cisões e dilemas; a dissolução do eu pelo desassossego provoca um devir-outro múltiplo - por isso no Livro do Desassossego, nascem, aqui e ali, a escrita de Campos, a de Ricardo Reis. Pelo contrário, a petrificação do eu no tédio é, muitas vezes, assimilada por Bernardo Soares à impossibilidade de se tornar outro - como se o devir-outro o libertasse do horror do tédio. Isto é, o tédio é o cárcere de que o eu se enquista, incapaz de entrar no movimento do sonho que o torna outro. O tédio é o rebatimento do eu petrificado sobre todas as coisas em todos os tempos, e o horror de viver que o acompanha vem desse não poder deixar de ser eu." (GIL, 2013, p. 113-114).
} 


\section{Aemergência do tédio}

A tarefa de caracterizar as eventuais causas ou origens do tédio depara-se com uma barreira imediata, porque Bernardo Soares fala da possibilidade da aparição do tédio de maneira espontânea e sem razão (PESSOA, 2013, n. 98, 263). Apesar disso, conforme o fragmento 184, dá para ser constatado que um dos motivos da manifestação do estado de aborrecimento generalizado no Livro do desassossego está relacionado com a mudança das estações. Soares pontua que, com a quase chegada do outono, invadem-lhe as sensações intensas de "desolação sem lugar", "naufrágio da alma", "perda do Deus complacente", "morte da Substância de tudo". Ele sente a profundez desesperada na qual se encontra e afirma que nada é capaz de consolá-lo.

Antes que o estio cesse e chegue o outono, no cálido intervalo em que o ar pesa e as cores abrandam, as tardes costumam usar um traje sensível de gloríola falsa. [...] Nessas tardes enche-me, como um mar em maré, um sentimento pior que o tédio mas a que não compete outro nome senão tédio. [...] O meu tédio assume aspectos de horror; o meu aborrecimento é um medo. O meu suor não é frio, mas é fria a minha consciência do meu suor. Não é um mal-estar físico, salvo que o mal-estar da alma é tão grande que passa pelos poros do corpo e o inunda a ele também. É tão magno o tédio, tão soberano o horror de estar vivo, que não concebo que coisa haja que pudesse servir de lenitivo, de antídoto, de bálsamo ou esquecimento para ele. Dormir horroriza-me como tudo. Morrer horroriza-me como tudo. Ir e parar são a mesma coisa impossível. Esperar e descrer equivalem-se em frio e cinza. Sou uma prateleira de frascos vazios. (PESSOA, 2013, n. 184)

Embora a proximidade do outono lhe seja angustiante, Soares não vê a iminência do verão sob a perspectiva do regozijo. Ao contrário, ele declara: "Quando o estio entra entristeço". Parece que a luminosidade, ainda que acre, das horas estivais devera acarinhar quem não sabe quem é. Mas não, a mim não acarinha." (PESSOA, 2013, n. 465). O abatimento e a profunda tristeza se lhe manifestam, pois verifica o desequilíbrio entre a vida exterior que floresce e exubera e aquilo que, no seu interior, ele realmente pensa e sente. A questão sazonal pode ser vista como alheia 
à vontade do Ajudante de guarda-livros na cidade de Lisboa, mas que $\mathrm{o}$ afeta demasiadamente.

Existem também ocorrências do estado tedioso associadas às atitudes, condutas e percepções de Bernardo Soares. Elas podem ser tipificadas como a dedicação ou a preocupação com o que é ordinário ou banal. Exemplos disto são, em primeiro lugar, o exercício das atividades corriqueiras e ao seu trabalho ordinário no escritório como guarda-livros. Em segundo, o viajar que, na sua opinião, traz a enganadora imagem da novidade e da diferença das coisas, mas que na verdade não passa da constante repetição do mesmo, de formas de contrariedade e de chances para a náusea e o cansaço.

Às vezes, quando ergo a cabeça estonteada dos livros em que escrevo as contas alheias e a ausência de vida própria, sinto uma náusea física, que pode ser de me curvar, mas que transcende os números e a desilusão. A vida desgosta-me como um remédio inútil (PESSOA, 2013, n. 106). A ideia de viajar nauseia-me. Já vi tudo que nunca tinha visto. Já vi tudo que ainda não vi. $O$ tédio do constantemente novo, o tédio de descobrir, sob a falsa diferença das coisas e das ideias, a perene identidade de tudo, a semelhança absoluta entre a mesquita, o templo e a igreja, a igualdade da cabana e do castelo, o mesmo corpo estrutural a ser rei vestido e selvagem nu, a eterna concordância da vida consigo mesma, a estagnação de tudo que vive só de mexer-se. Paisagens são repetições. (PESSOA, 2013, n. 122)

Outro aspecto que pode ser associado às manifestações do tédio na vida de Bernardo Soares encontra-se na ordem das relações humanas. No fragmento 235 , ele, Soares, admite a sua incapacidade e sua impaciência para se ligar a alguém, através de um apreço ou sentimento contínuo que implique compromisso ou reciprocidade. Na sua visão, a realidade do afeto por alguém constitui uma condição de fadiga e ou forma de aprisionamento. $\mathrm{Na}$ ânsia de autonomia e liberdade, ele quer se ver livre de ser "o objeto do fardo das emoções alheias" e de enxergar a sua existência como que dependente de uma afeição para com outrem.

O isolamento talhou-me à sua imagem e semelhança. A presença de outra pessoa - de uma só pessoa que seja - atrasa-me imediatamente o pensamento [...]. Sou 
capaz, a sós comigo, de idear quantos ditos de espírito, respostas rápidas ao que ninguém disse, fulgurações de uma sociabilidade inteligente com pessoa nenhuma; mas tudo isso se me some se estou perante a outrem físico, perco a inteligência, deixo de poder dizer, e, no fim de uns quartos de hora, sinto apenas sono. Sim, falar com gente dá-me vontade de dormir. Só os meus amigos espectrais e imaginados, só as minhas conversas decorrentes em sonho, têm verdadeira realidade e um justo relevo, e neles o espírito é presente como a imagem num espelho. Pesa-me, aliás, toda a ideia de ser forçado a um contacto com outrem. Um simples convite para jantar com um amigo me produz uma angústia difícil de definir. A ideia de uma obrigação social qualquer - ir a um enterro, tratar junto de alguém de uma coisa do escritório, ir esperar à estação uma pessoa qualquer, conhecida ou desconhecida -, só essa ideia me estorva os pensamentos de um dia, e às vezes é desde a mesma véspera que me preocupo, e durmo mal, e o caso real, quando se dá, é absolutamente insignificante, não justifica nada; e o caso repete-se e eu não aprendo nunca a aprender. (PESSOA, 2013, n. 49).

Afora a vinculação afetiva de natureza mais direta, Soares aponta o advento do tédio, no horizonte das relações com os outros, ao contemplar as pessoas que se devotam à humanidade, não prezando a realidade íntima de suas próprias almas. E, ao tratar das guerras e revoluções, declara que o que lhe causa o nauseamento não são as crueldades e as mortes daqueles que se envolvem nas batalhas. O que lhe entedia é a estupidez do sacrifício de vidas e projetos por aquilo que é inútil, pois os ideais e as ambições são completos desvarios e mostras da absoluta falta de sentido. Conforme o Guarda-livros lisboeta, a civilização, enquanto expressão do ordinário e quotidiano, é sempre a mesma realidade paradoxal: variável, mas não se aperfeiçoa; oscilante, mas não progride (PESSOA, 2013, n. 45,454$)$.

\section{0 afastamento do tédio}

Como distanciar-se do tédio? Esta é uma pergunta relevante no contexto do Livro do desassossego. Se tomamos em consideração o sentirse entediado enquanto algo que perturba Bernardo Soares e o cultivo da 
interioridade como o que, segundo ele, constitui o que realmente importa na vida, as suas disposições e atitudes pessoais em relação ao cuidado com a realidade suprema da alma podem indicar perspectivas interessantes acerca do lidar com o aborrecimento generalizado que sufoca e oprime a sua existência.

A primeira a ser considerada relaciona-se à estética. Bernardo Soares defende a missão emancipadora da grande arte que, na sua visão, resume-se na poesia e no romance. Uma das maneiras que ele se vale para se apartar do tédio e viver uma vida interior significativa é através da literatura. A leitura dos clássicos favorece-lhe a concentração e a libertação. $\mathrm{O}$ contato com o texto proporciona-lhe a abdicação do sentimento entediante e sua vida amplia-se em significado. A criação literária também colabora na sua aquietação, pois consegue transmitir, mediante os escritos, suas emoções mais sinceras, fingindo sempre, algo que não alcança na comunicação oral. E é, justamente, no segundo andar do edifício na Rua dos Douradores, local onde mora não somente a Vida, mas a Arte, que o Ajudante de guarda-livros encontra o espaço adequado e a solidão propícia para transpor para o papel a pluralidade do seu ser mais profundo e seus sonhos mais reais.

Viver uma vida desapaixonada e culta, ao relento das ideias, lendo, sonhando, e pensando em escrever, uma vida suficientemente lenta para estar sempre à beira do tédio, bastante meditada para nunca se encontrar nele (PESSOA, 2013, n. 45); Leio e estou liberto. Adquiro obectividade. Deixei de ser eu e disperso. E o que leio, em vez de ser um trajo meu que mal vejo e por vezes me pesa, é a grande clareza do mundo externo, toda ela notável [...] (PESSOA, 2013, n. 55); Como há quem trabalhe de tédio, escrevo, por vezes, de não ter que dizer. O devaneio, em que naturalmente se perde quem não pensa, perco-me eu nele por escrito, pois sei sonhar em proza. E há muito sentimento sincero, muita emoção legítima, que tiro de não estar sentindo (PESSOA, 2013, n. 155).

Um possível segundo modo de superação do tédio e de conservação de si mesmo tem a ver com a resignação e a indiferença. Soares aborda estes temas em situações anteriores de seu texto, entretanto, no fragmento 426, explora mais claramente o assunto. De acordo com ele, configura-se princípio de sabedoria a tomada de consciência de que 
a maior angústia pessoal não passa de um mero incidente na vida do universo e na própria alma individual. Embora entenda que, em ocasiões de aflição esgotante, a dor seja sentida como infinita, Bernardo Soares assevera que infinitude não é uma qualidade adequada a tal experiência, pois não há nada na realidade humana que não tenha fim. E declara que a dor que se sente é apenas uma dor (PESSOA, 2013, n. 106, 365, 426).

Para alguns que me falam e me ouvem, sou um insensível. Sou, porém, mais sensível - creio - que a vasta maioria dos homens. O que sou, contudo, é um sensível que se conhece, e que, portanto, conhece a sensibilidade. Ah, não é verdade que a vida seja dolorosa, ou que seja doloroso pensar na vida. O que é verdade é que a nossa dor só é séria e grave quando a fingimos tal. Se formos naturais, ela passará assim como veio, esbater-se-á assim como cresceu. Tudo é nada, e a nossa dor nele. (PESSOA, 2013, n. 426)

O Livro do desassossego deixa entrever a necessidade de se parar diante da dor e do tédio, tomar consciência de si e sentir quem realmente se é. Este caminho de sensibilização parece funcionar como um afastamento da realidade entediante, ao mesmo tempo que concede ao sujeito que o empreende a razão da proporcionalidade do que lhe ocorre e, sobretudo, o entendimento de que isto é nada. Ao que consta, Bernardo Soares está a descrever algo análogo à elevação espiritual ou ao distanciar-se de si mesmo, que conduz à percepção do caráter efêmero e circunstancial do que compõe a existência. Ademais, ele afirma que redige o seu texto sob a pressão de um tédio quase a transbordar, todavia, ao autoperceber-se, enxerga-se diferente, liberto e tornado outro de si (PESSOA, 2013, n. 426).

$\mathrm{Na}$ esteira da resignação e da indiferença, existem duas outras reflexões feitas por Bernardo Soares a respeito da associação entre o sentir-se entediado e o não fazer nada, que merecem ser destacadas. Em contraposição aos que declaram o estado entediante como uma doença que afeta inertes e desocupados, ele responde que este sutil mal da alma aflige somente os que se encontram à altura dele, ou seja, os grandes esforçados. A cruel doença atormenta os que estão cientes dela e sentem que não podem fazer absolutamente nada ou, o que é pior, sabem que "quanto mais há que fazer, mais tédio há que sentir." (PESSOA, 2013, n. 445). 
O estar chateado por não ter o que fazer não se configura como o verdadeiro tédio. Isto é exemplificado por Bernardo Soares mediante as constatações de Omar Khayyan, que identifica tudo no mundo como obscuro; através das palavras de Salomão, que afirma a vaidade e a transitoriedade inexorável do que existe; e pelas declarações de Séptimo Severo que, tendo oportunidade para ser tudo o que quis, conclui que nada compensa. Diante deste cenário, não resta outra coisa ao indivíduo, senão a disciplina da vontade, a impassibilidade e a conformação ao que acontece (PESSOA, 2013, n. 446).

Além das posições acenadas, outras atitudes de contorno do tédio encampadas por Soares parecem ter sido a separação afetiva e a recusa do viajar. Ambos casos eram, para ele, verdadeiramente, entediantes. Os amores, ele procurou cultivá-los nos seus sonhos. E é significativo que no fragmento 345 relata a sua experiência onírica com a pessoa amada sob a imagética religiosa: "Que o nosso amor seja uma oração... Unge-me de ver-te que eu farei dos meus momentos de te sonhar um rosário onde os meus tédios serão padre-nossos e as minhas angústias avé-marias...". Em se tratando das viagens, ele deve tê-las cumprido segundo os recursos da sensibilidade e da imaginação (PESSOA, 2013, n. 122).

Por fim, como no espaço da vida exterior não há muito o que possa ser feito para afastar o tédio, exceto o acatamento resignado da vacuidade de sentido de todas as coisas, Bernardo Soares afirma o seu universo interior como o locus das possibilidades. Tudo o que deseja ele consegue, desde que seja dentro de si. Sobretudo porque se reconhece como a encarnação do estado entediante, o fato de criar distintas personalidades, com o intuito de expressar seus profundos sentimentos, pode ser visto como uma de suas tentativas de viver neste mundo de modo que o tédio não lhe doesse tanto. O que nos parece que para Soares, a criação literária é a sua salvação (PESSOA, 2013, n. 122, 215, 404).

\section{Considerações finais}

Esta síntese assumiu como objetivo considerar, a partir do Livro do desassossego, o estado entediado, sob as perspectivas da sua compreensão, das causas de sua manifestação e das tentativas ou atitudes convenientes para a sua superação. Na exposição do assunto, foi possível perceber que Bernardo Soares atribui ao termo em tela uma significação bastante plural. Na verdade, o tédio figura no conjunto da obra como um 
termo polivalente, cujo papel principal relaciona-se à tradução metafórica da constatação dramática da vacuidade de sentido existencial. Conforme foi visto, o sentir-se entediado comporta os sentimentos de infelicidade, confusão, pessimismo, tristeza, desilusão, abandono, sufocamento. Trata-se de uma disposição de aborrecimento generalizado acerca do existir, a qual se encerra na tomada de consciência do caráter caótico de todas as coisas, inclusive de sua própria vida. Uma das imagens mais fortes e intensas que ele utiliza para descrever o seu ser enfadado é a personificação de si mesmo enquanto o tédio.

O segundo passo da abordagem buscou demonstrar as situações que promovem estado entediante para o Ajudante de guarda-livros na cidade de Lisboa. Não obstante os casos de manifestação espontânea do tédio, o estudo verificou a mudança das estações, sobretudo as proximidades do outono e do verão, como um tipo de causa de natureza exterior. Numa perspectiva mais aliada à vontade de BernardoSoares, percebeu-se que o nauseamento lhe ocorre quando se envolve na consecução de coisas ordinárias ou mais banais, tais como a lida no escritório ou a realização, mesmo hipotética, de viagens. Ademais, a análise feita foi capaz de identificar o aparecimento do seu estado entediado no contexto do relacionamento humano, seja vivido no contato afetivo com os outros ou contemplado no modo como as pessoas olvidamse da dimensão íntima da existência e conduzem suas vidas ocupadas com o que, para ele, é inútil e estúpido.

Por último, as investigações sobre as possibilidades de superação do tédio tomaram como referências as atitudes de Bernardo Soares relacionadas ao cuidado da alma interior, capaz de viajar imóvel, sonhar e escrever vidas plurais em mundos outros. Assim, a sua dedicação à literatura, tanto na leitura dos clássicos quanto no ato de escrever, parece lhe propiciar um alento significativo. Outro dado reconhecido foi o da simples acolhida da constituição tediosa e sem sentido da realidade desordenada de todas as coisas, por constatar o quanto a luta contra o tédio somente promove a sua intensificação. Desde quando apenas na sua interioridade é que encontra sentido, ou falta dele, para a sua existência. Tal horizonte encampa, na obra, entre outros aspectos, desde a sua realização amorosa e afetiva de matriz onírica até a criação de outros de si, mediante a força da heteronímia e sua diversificação em pessoas distintas, passando ainda pelas suas incursões e viagens imaginárias, sem sair da morada da Arte, no $2^{\circ}$ andar da Rua dos Douradores. 


\section{Referências}

GIL, José. Cansaço, tédio, desassossego. Lisboa: Relógio d'Água, 2013. PESSOA, Fernando. Livro do desassossego: composto por Bernardo Soares, ajudante de guarda-livros na cidade de Lisboa. 11 ${ }^{\mathrm{a}}$. edição. Porto: Assírio e Alvim, 2013.

SERRÃO, Joel. Temas de cultura portuguesa. Lisboa: Livros Horizonte, 1983. 